\title{
Estimation of Genetic Parameters for Some Production and Reproduction Traits Using Different Animal Models in Egyptian Buffaloes Mostafa, M. A. ; S. A. Darwish ${ }^{2}$ and M. S Abd El-Fatah ${ }^{1}$ ${ }^{1}$ Animal Production Dept., Fac. of Agric., Mansoura University \\ ${ }^{2}$ Animal Production Research Institute, Agriculture Research Center, Ministry of Agriculture, Egypt.
}

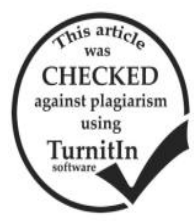

\begin{abstract}
Estimates of (co)variance component and genetic parameters using multi-traits animal model, traits studied were lactation period (LP), total lactation milk yield (TMY), and days open (DO). In all lactations based on 4745 records of Egyptian buffaloes calved during the period from 1980 to 2014 at Mehallet Mousa Experimental farms of Animal Production Research Institute (APRI), Ministry of Agriculture. The six mixed model used in the analysis included the non genetic effects of month and year of calving, parity, and the random effects of additive direct genetics, maternal effect, maternal permanent environmental and residual. Means for LP, TMY and Do were $220.632 \mathrm{~d}, 1445.26 \mathrm{~kg}$ and $184.34 \mathrm{~d}$, respectively. The estimates of heritability in six models for LP, TMY and Do were ranged from $(0.026 \pm 0.56$ to $0.047 \pm 0.16),(0.15 \pm 0.57$ to $0.021 \pm 0.15)$ and $(0.02 \pm 0.020$ to $0.020 \pm 0.13)$, respectively. While Estimates of maternal heritability was very low in six models for LP, TMY and DO and ranged from $0.055 \pm 0.026$ to $0.18 \mathrm{E}-09 \pm 0.79 \mathrm{E}-05$ : $0.081 \pm 0.029$ to $0.52 \mathrm{E}-09 \pm 0.13 \mathrm{E}-04 ; 0.053 \pm 0.01$ to $0.83 \mathrm{E}-09 \pm 0.12 \mathrm{E}-04$, respectively. The estimates of genetic correlations between LP and TMY in six models ranged from (0.53 to 0.84). Estimates of genetic correlation between DO and TMY in six models ranged from ( -0.15 to 0.58$)$. While the estimates of genetic correlation between LP and DO in six models ranged from (0.30 to 0.94). Corresponding estimates of phenotypic correlation among same traits fluctuated (0.17 to 76). Thus, the influence of the maternal genetic effect for traits studied was lowest thereby no relative efficiency of improvement. Vice-versa, direct heritabilities for TMY and LP were efficiency, therefore considerable rate of genetic improvement these traits under investigation. Genetic betterment for LP following up improve each TMY and DO. The estimates of heritabilities were low for DO indicated that the major part of the variation in this trait was environmental and selection may not prove effective in bringing about genetic improvement. Therefore, preferable improving management can play a major role in this trait.
\end{abstract}

Keywords:Lactation period, total Milk yield, Days open, maternal heritability, direct additive heritability and Egyptian buffaloes.

\section{INTRODUCTION}

It is well known that the buffalo in Egypt is a major source for the production of milk and red meat in Egypt, contributes to buffalo about $47 \%$ of the total milk production the National (Mostafa et al., 2012). The total numbers of buffaloes nearly 3.95 million buffalo (Marl., 2016). Milk production and Reproductive traits are the most important traits that influence profitability of dairy production (Mark et al., 2002, Haile-Mariam et al., 2003 and Zafar et al ., 2008), revealing the production potential of a particular animal. However, stage of lactation and parity of animal and season of calving are some other main factors, which influence milk production and its composition in cattle buffalo and goat. (Ibeawuchi and Dangut 1996; Ekerden Ozel 1999 and Akingbade et al., 2003). Nevertheless, genetic improvement of productivity and reproductive traits is almost non-existent in Egypt. Even some improvement programs for increasing dairy yield have been implemented, they have not survived due to the lack of financial resources, (García et al., 2002; Grajales et al., 2006). The objectives of this study were to determine the genetic, phenotypic parameters for Lactation period (LP), total Milk Yield (TMY) and Days open (DO) using different model of animal model in Egyptian buffalo.

\section{MATERIALS AND METHODS}

Data collected from Egyptian buffaloes kept at maintained at Mehallet Mousa Experimental farms of Animal Production Research Institute (APRI), Ministry of Agriculture Egypt. The data of 1428 buffaloes having 4745 normal lactation records from one to nine lactations over a period of 35 years from 1980 to 2014 were included in this investigation. The numbers of sires and dam were 255 and 1300, respectively. Buffaloes records were included sires and dams identification, month and year of calving, farm, parity, lactation period (LP), total milk yield (TMY) and days open (DO). Buffaloes were naturally mated until 2002 and artificially insemination after that. Assignment of sires to buffaloes was at random. Heifers were served for the first time when they reached 24 month or $350 \mathrm{~kg}$ of weight. Traits studied were total lactation milk yield (TMY), lactation period (LP) and days open (DO).

\section{Management of the herds}

Animals were kept under Semi- open asbestos sheds. Lactating buffaloes were milked by hand or machine twice daily at 7.00 a. $\mathrm{m}$ and $4.00 \mathrm{p} . \mathrm{m}$ throughout the lactation period and milk production was recorded daily. Buffaloes were kept under the routine feeding with according to level of production and managerial system in mahallet mousa experimental farms. The Animals were grazed on Egyptian clover (Trifolium alexandrinum) during December to May with concentrate mixture and rice. While during June to November, animals were fed on concentrate mixture, rice straw and limited amount of clover hay or (silage). Animals were feed according to their live weight, milk production and reproductive status. The concentrate feed mixture was given twice daily before milking, while rice straw was offered once daily at 9.00 a. m, whereas clover hay or (silage) in summer was offered at 11.00 a. $\mathrm{m}$, animals were allowed to drink water three 
times a day or free from water troughs. Multi mineral licking blocks were available for animals in the stalls.

\section{Data analyses}

Data analyzed using multi-traits animal model of VCE6 computer package (Groeneveld et al., 2010) for estimate variance components for direct, maternal and environmental effects by Restricted Maximum Likelihood procedures (REML) and fitting six different animal models.

The model 1: included additive direct effect

$$
\mathrm{Y}=\mathrm{Xb}+\mathrm{Za}+\mathrm{e}
$$

The model 2: included additive direct effect and the environmental effect. maternal permanent

$$
\mathrm{Y}=\mathrm{Xb}+\mathrm{Za}+\text { Wpe }+\mathrm{e}
$$

The model, 3: included a additive direct effect and additive maternal effect

$$
\mathrm{Y}=\mathrm{Xb}+\mathrm{Za}+\mathrm{Zm}+\mathrm{e} \text { with } \operatorname{Cov}(\mathrm{a}, \mathrm{m})=0
$$

The model 4: was the same as Model 3, but allowed for a direct maternal covariance $((\operatorname{Cov}(\mathrm{a}, \mathrm{m}))$

$$
\mathrm{Y}=\mathrm{Xb}+\mathrm{Za}+\mathrm{Zm}+\mathrm{e} \text { with } \operatorname{Cov}(\mathrm{a}, \mathrm{m})=0
$$

The model 5: included additive direct effect, additive maternal and maternal permanent environmental effects, ignoring the direct-maternal covariance.

$\mathrm{Y}=\mathrm{Xb}+\mathrm{Za}+Z m+W p e+\mathrm{e}$ with $\operatorname{Cov}(\mathrm{a}, \mathrm{m})=0$

The model 6: included additive direct effect, additive maternal and maternal permanent environmental effects, with fitting direct - maternal covariance.

$\mathrm{Y}=\mathrm{Xb}+\mathrm{Za}+\mathrm{Zm}+$ Wpe $+\mathrm{e}$ with $\operatorname{Cov}(\mathrm{a}, \mathrm{m})=0$

Where, $\mathrm{Y}=$ is the vector of traits studies. $\mathrm{b}=$ is the vector of available fixed effects (i.e. year of calving, month of calving and parity). $\mathrm{a}=$ is the vector of breeding value, $\mathrm{m}=$ is the random vector of direct maternal effects, $\mathrm{pe}=$ is the random vector of maternal permanent environmental effects, $\mathrm{X}, \mathrm{Za}$, and $\mathrm{Zm}=$ are the incidence matrices relating records to examined fixed, animal additive maternal effect and random maternal permanent environmental effects, respectively, and, $\mathrm{e}=$ is the unknown vector of residual effects.

\section{RESULTS AND DISCUSSION}

The overall means and their standard deviations (SD) and coefficient variabilities (C.V) for different studied traits are presented in Table 1. The overall means for LP, TMY and Do were $220.63 \mathrm{~d}, 1445.26 \mathrm{~kg}$, $184.34 \mathrm{~d}$, respectively. The present estimated of LP was higher than obtained by Mourad and Khattab, (2009) in Egyptian buffaloes (184 days). However, lower than estimated by Bashir et al., (2015) was 278.3 days and Barros et al., (2016) was 269.57 day in buffalo. Mean of total milk yield (TMY) was lower than found by Mostafa et al., (2012) (1943) and Bashir et al., (2015) in Pakistan $(1840 \pm 08 \mathrm{~kg})$ working on buffaloes. The present mean of DO is higher than that found by Damarany et al., (2013) (141.8d) and Marai et al., (2009) (91.8 $\pm 1.3 \mathrm{~d})$ for Egyptian buffaloes. This study revealed that high coefficients of variation (ranged from
37.20 to $70.46 \%$ ). Such large coefficients of variation are good opportunities for breeders to improve in these traits.

Table 1.The estimated of overall means, standard deviations (SD) and coefficient variabilities (C.V) for lactation period (LP), Total milk yield (TMY) and day open (DO).

\begin{tabular}{lcccc}
\hline Traits & Records & Mean & SD & C.V\% \\
\hline LP (day) & 4745 & 220.63 & 82.07 & 37.20 \\
TMY (kg) & 4745 & 1445.26 & 629.69 & 43.57 \\
DO (day) & 3499 & 184.34 & 129.89 & 70.46 \\
\hline
\end{tabular}

Estimates of (co)variances components and heritabilities for different traits studied are presented in Table (2). The estimates of direct heritability for LP in six models ranged from $0.16 \pm 0.047$ to $0.56 \pm 0.026$, the higher value of estimates in model 4 , while the lowest value are recorded in model 2. The present estimate of direct heritability of similar estimated by El-Arian et al., (2012) $(0.41+0.06)$ on Egyptian buffaloes, while our findings are higher than estimated by Mourad and Khattab (2009) (0.134) and El-Bramony, (2014) (0.06) in Egyptian buffaloes. The estimates of present direct heritability of TMY round from $0.15 \pm 0.021$ to $0.57 \pm 0.15$, similar estimates were reported by Mourad and Khattab (2009) 0.172 on Egyptian buffaloes and Barros et al., (2016) (0.24) on Murrah Buffaloes .The direct heritability of DO higher than estimate by Birhanu et al (2015) was $0.119 \pm 0.0335$ on Holstein Friesian and that of Aziz et al., (2001) 0.08 on Egyptian buffalo, which ranged from $0.13 \pm 0.020$ to $0.20 \pm 0.02$ in present results. Estimates of maternal heritability was very low in six models for LP, TMY and DO and ranged from $0.18 \mathrm{E}-09 \pm 0.79 \mathrm{E}-05$ to $0.055 \pm 0.026$; $0.52 \mathrm{E}-$ $09 \pm 0.13 \mathrm{E}-04$ and $0.081 \pm 0.029$ and from $0.83 \mathrm{E}-$ $09 \pm 0.12 \mathrm{E}-04$ to $0.053 \pm 0.01$, respectively. These results agree with Khattab et al. (2005) and Mostafa et al., (2013) suggested that maternal effects are not important for milk traits in dairy cattle.

The estimates herein for maternal heritability similar those obtained by Khattab et al., (2005) for (305dMY) on Holstein Friesian in two models were $0.01,0.02$, respectively. Lee et al., (2004) estimated for $305 \mathrm{dMY}$ and DO (0.045 and 0.005 , respectively) on Korean Holstein cows and Berry et al., (2008) for TMY on Holstein Friesian 0.01.

\section{Correlations}

Direct genetic correlations and maternal genetic correlations of studied traits in Egyptian buffaloes are given in Table 3 .

Estimates of direct genetic correlations between LP and TMY for six model ranged from 0.53 to 0.84 . These results agree with genetic correlation estimated between LP and TMY in Egyptian buffalo by Mostafa et al., (2012) was (0.75), El-Arian et al., (2012) (0.75) and Khattab et al., (2003) (0.76). The genetic correlations estimates between TMY and DO in six models ranged from $(-0.15$ to 0.58$)$. While the estimate obtained by Hammoud et al., (2013) on Egyptian Holstein cows was negative $(-0.31)$. 
Table 2. Estimates of direct and maternal heritabilities, ratios of permanent variance and covariance between direct and maternal genetic effect for different studied traits in Egyptian buffalo.

\begin{tabular}{|c|c|c|c|c|c|c|c|c|c|c|c|}
\hline Trait/Estimates & Model & $\sigma_{a}^{2}$ & $\sigma_{c}^{2}$ & $\sigma_{m}^{2}$ & $\sigma_{\text {a m }}$ & $\sigma_{e}^{2}$ & $\sigma_{p}^{2}$ & $\mathbf{h}_{\mathrm{a}}^{2} \pm \mathrm{SE}$ & $\mathrm{c}^{2} \pm \mathrm{SE}$ & $\mathbf{h}_{\mathrm{m}}^{2} \pm \mathrm{SE}$ & $\mathbf{r}_{\mathrm{am}} \pm \mathbf{S E}$ \\
\hline \multirow{6}{*}{ LP } & 1 & 2598 & & & & 3987 & 6585 & $0.39 \pm 0.021$ & & & \\
\hline & 2 & 1024.8 & 1236.0 & & & 3889 & 6150 & $0.16 \pm 0.047$ & $0.20 \pm 0.077$ & & \\
\hline & 3 & 2187 & & 318.2 & & 3971 & 6476 & $0.34 \pm 0.031$ & & $0.049 \pm 0.028$ & \\
\hline & 4 & 3127 & & 313 & -827 & 3941 & 5727 & $0.56 \pm 0.026$ & & $0.055 \pm 0.026$ & $-0.84 \pm 0.19$ \\
\hline & 5 & 1106.4 & 1167.9 & $0.1077 \mathrm{E}-05$ & & 3905 & 6179 & $0.18 \pm 0.024$ & $0.19 \pm 0.23$ & $0.18 \mathrm{E}-09 \pm 0.79 \mathrm{E}-05$ & \\
\hline & 6 & 1215.9 & 1183.0 & 41.1 & -167.5 & 3886 & 5991 & $0.21 \pm 0.04$ & $0.19 \pm 0.03$ & $0.01 \pm 0.008$ & $-0.75 \pm 0.25$ \\
\hline \multirow{6}{*}{ TMY } & 1 & 145644 & & & & 216981 & 362624 & $0.41 \pm 0.018$ & & & \\
\hline & 2 & 494292.5 & 79244.0 & & & 211026 & 339700 & $0.15 \pm 0.035$ & $0.24 \pm 0.054$ & & \\
\hline & 3 & 112368 & & 27107.5 & & 215476 & 354952 & $0.32 \pm 0.031$ & & $0.076 \pm 0.028$ & \\
\hline & 4 & 176603 & & 24786 & -54555 & 213653 & 305932 & $0.57 \pm 0.03$ & & $0.081 \pm 0.029$ & $-0.83 \pm 0.16$ \\
\hline & 5 & 52862.9 & 76238.7 & $0.1769 \mathrm{E}-03$ & & 211572 & 340674 & $0.15 \pm 0.021$ & $0.23 \pm 0.02$ & $0.52 \mathrm{E}-09 \pm 0.13 \mathrm{E}-04$ & \\
\hline & 6 & 58492.6 & 74705.4 & 1721.6 & -5622.9 & 210969 & 334642 & $0.17 \pm 0.03$ & $0.22 \pm 0.02$ & $0.01 \pm 0.005$ & $-0.56 \pm 0.47$ \\
\hline \multirow{6}{*}{ DO } & 1 & 1797 & & & & 11310 & 13107 & $0.14 \pm 0.019$ & & & \\
\hline & 2 & 1655.9 & 81.6 & & & 1655.9 & 13043 & $0.13 \pm 0.026$ & $0.04 \pm 0.03$ & & \\
\hline & 3 & 1750 & & 21.3 & & 11313 & 13084 & $0.14 \pm 0.033$ & & $0.01 \pm 00$ & \\
\hline & 4 & 2389 & & 636 & -1074 & 11163 & 12041 & $0.20 \pm 0.02$ & & $0.053 \pm 0.01$ & $-0.87 \pm 0.69$ \\
\hline & 5 & 1664.0 & 75.3 & $0.1081 \mathrm{E}-04$ & & 113085 & 13048 & $0.13 \pm 0.020$ & $0.01 \pm 0.02$ & $0.83 \mathrm{E}-09 \pm 0.12 \mathrm{E}-04$ & \\
\hline & 6 & 2207.4 & 150.8 & 617.4 & -1064 & 11184 & 11996 & $0.18 \pm 0.02$ & $0.01 \pm 0.07$ & $0.05 \pm 0.02$ & $-0.91 \pm 0.06$ \\
\hline
\end{tabular}

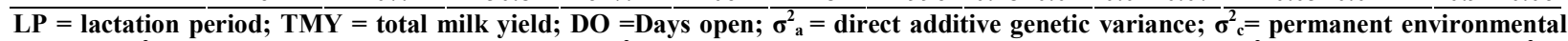
variance; $\sigma_{m}^{2}=$ maternal additive genetic variance; $\sigma_{a m}^{2}=$ direct and maternal additive genetic covariance; $\sigma^{2}=$ residual variance; $\sigma_{p}^{2}=$ phenotypic variance; $c 2=$ permanent environmental variance as a proportion of phenotypic variance.; $h^{2}=d^{2}$ direct heritability; $h^{2}{ }_{m}=$ maternal heritability; $r_{a m}=$ correlation between direct and maternal additive genetic effect.

Genetic correlations between LP and DO in six models was positive $(0.30$ to 0.94$)$ and higher than obtained by Aziz et al., (2001) (0.07) on Egyptian buffaloes. The estimates of maternal genetic correlations between (LP and TMY), (TMY and DO) and (LP and DO) in six models ranged from (0.66 to $0.99),(-0.87$ to 0.52$)$ and (-0.85 to 0.61$)$ respectively.

Phenotypic correlations of studied traits in Egyptian buffaloes are given in Table 4.

The estimates of phenotypic correlations between LP and TMY in six models were high, positive from
( 0.74 to 0.76$)$, and similar to that estimated by Marai et al., (2009) (0.77) on Egyptian buffaloes. Phenotypic correlation between (TMY and DO) and (LP and DO) ranged from (0.17 to 0.21$)$ and from (0.27 to 0.29$)$, respectively. These results agree with that of Dematawewa and Berger (1998), found the Estimates of phenotypic correlation between TMY and DO was 0.27 on Holstein cows. However the phenotypic correlations between LP and DO was lower than that reported by Aziz et al., (2001) (0.47) on Egyptian buffalos.

Table 3. Estimates of direct genetic correlations and maternal genetic correlations of studied traits for six models in Egyptian buffaloes.

\begin{tabular}{lcccccccccc}
\hline \multirow{2}{*}{ Traits } & Model 1 & Model 2 & \multicolumn{2}{c}{ Model 3 } & \multicolumn{2}{c}{ Model 4 } & \multicolumn{2}{c}{ Model 5 } & \multicolumn{2}{c}{ Model 6 } \\
& $\mathbf{r}_{\mathbf{G}}$ & \multicolumn{1}{c}{$\mathbf{r}_{\mathbf{G}}$} & $\mathbf{r}_{\mathbf{G}}$ & $\mathbf{r}_{\mathbf{m g}}$ & $\mathbf{r}_{\mathbf{G}}$ & $\mathbf{r}_{\mathbf{m g}}$ & $\mathbf{r}_{\mathbf{G}}$ & \multicolumn{1}{r}{$\mathbf{r}_{\mathbf{m g}}$} & $\mathbf{r}_{\mathbf{G}}$ & $\mathbf{r}_{\mathbf{m g}}$ \\
\hline LP X TMY & 0.82 & 0.53 & 0.78 & 0.99 & 0.84 & 0.96 & 0.56 & 0.95 & 0.57 & 0.66 \\
TMY x DO & 0.26 & 0.58 & 0.23 & 0.12 & 0.16 & 0.52 & 0.097 & -0.87 & -0.15 & -0.15 \\
LP x DO & 0.94 & 0.46 & 0.47 & 0.12 & 0.41 & 0.31 & 0.45 & -0.85 & 0.30 & 0.61 \\
\hline
\end{tabular}

$\mathbf{r}_{\mathrm{G}}=$ direct genetic correlations; $r_{\mathrm{mg}}=$ Maternal genetic correlations

Table 4. Estimates of phenotypic correlations of studied traits for six models in Egyptian buffaloes.

\begin{tabular}{|c|c|c|c|c|c|c|}
\hline Traits & $\begin{array}{l}\bar{D} \\
\frac{\sigma}{\delta} \\
\Sigma\end{array}$ & $\frac{N}{\frac{0}{0}}$ & $\frac{\infty}{\frac{e}{\sigma}}$ & $\frac{ \pm}{\frac{D}{\sigma}}$ & $\frac{n}{\frac{0}{0}}$ & $\frac{0}{\frac{0}{0}}$ \\
\hline & $\mathbf{r}_{\mathbf{p}}$ & $\mathbf{r}_{\mathbf{p}}$ & $\mathbf{r}_{\mathbf{p}}$ & $\mathbf{r}_{\mathbf{p}}$ & $\mathbf{r}_{\mathbf{p}}$ & $\mathbf{r}_{\mathbf{p}}$ \\
\hline LP x TMY & 0.76 & 0.75 & 0.76 & 0.74 & 0.75 & 0.75 \\
\hline TMY x DO & 0.18 & 0.17 & 0.18 & 0.21 & 0.17 & 0.20 \\
\hline LP $x$ DO & 0.28 & 0.28 & 0.29 & 0.28 & 0.27 & 0.27 \\
\hline
\end{tabular}

Our results showed that the estimates of traits under investigation in unconditioned range with other studies in Egyptian buffaloes. The influence of the maternal genetic effect for traits studied was lowest thereby no relative efficiency of improvement. Viceversa, direct heritabilities for TMY and LP were efficiency, therefore considerable rate of genetic improvement these traits under investigation. Genetic betterment for LP following up improve each TMY and DO. The estimates of heritability was low for DO indicated that the major part of the variation in this trait was environmental and selection may not prove effective in bringing about genetic improvement. Therefore, preferable improving management can play a major role in this trait.

\section{REFERENCES}

Akingbade, A. A; Nsahlai, I .V and Morris, C. D. (2003). Composition of colostrums and milk of South African indigenous Nguni goats grazing natural pasture and supplemented with concentrate. J. of Animal Sci., 20: 47-51. 
Aziz, M. A; Schoeman, S. J.; Jordaan, G. F.; El-Chafie, O. M. and Mahdy, A.T. (2001). Genetic and phenotypic variation of some reproductive traits in Egyptian buffalo. South African J. of Animal Sci., 31: 195-199.

Barros, C.; Rusbel, R. S.; Fraga, B. A.; Tonhat, I. H. (2016). Genetic parameter estimates for production and reproduction traits in dairy buffaloes, Scientific Information System Network of Scientific J,Am, the Caribbean, Spain and Portugal, ISSN. 1983-2125. http://www.redalyc.org/articulo.oa?id=2371446250 25

Bashir, M. K; Khan, M. S.; Lateef, M. and Iqbal, M. (2015). Environmental factors affecting productive traits and their trends in NiliRavi Buffaloes. Pak. j. life Soc. Sci., 13: 137-144.

Berry, D. P; Lonergan, P.; Butler, S. T.; Cromie, A. R.; Fair, T., Mossa, F. and Evans, A. C. O. (2008). Negative influence of high maternal milk production before and after conception on offspring survival and milk production in dairy cattle. J. Dairy Sci Vol. 91: 329-337.

Birhanu, T.; Mohammed, T.; Kebede, K.; Tadesse, M. (2015). Heritability, genetic and phenotypic correlations of milk production and reproduction traits of Ethiopian boran cattle with different levels of Holstein Friesian inheritance, J. R. Infertility, 6: 79-83.

Damarany, A. I.; Ali, M. A. E. and Ammar R. M. (2013). Reproductive characteristics of the Baladi cows and buffaloes under traditional management conditions in Upper Egypt, the $4^{\text {th }}$ scientific conference of Animal Production Research Institute, 442-449.

Dematawewa, C. M. B. and Berger, P. J. (1998). Genetic and phenotypic parameters for 305-day yield, fertility and survival in Holsteins. J. Dairy Sci., 81: 2700-2709.

Ekerden, Ozel. (1999). Factors affecting milk composition and changes in milk composition with lactation stage in Anatolian buffaloes.Turkish J,Vet.Sci.,23:505-10. http://journals.tubitak.gov.tr/veterinary/issues/vet99-23-6/vet-23-6-1-96125.pdf.

El-Arian, M. N.; Shalaby, N. A. ; Khattab, A. S.; Darwish, S. A.; Abou-Gamous, R. H. (2012). Phenotypic and genetic trends for some milk yield traits of Egyptian buffaloes. J. Anim. Prod., 3: 353 - 364.

El-Bramony, M. (2014). Genetic and phenotypic parameters of milk yield and reproductive performance in the first three lactations of Egyptian buffalo. Egyptian J. Anim. Prod., 48: 1-10.

García, G. A.; Cárdenas, C. A.; Monterrosa, V.; Valencia, L. and Maldonado, J. G. (2002). Characterization productive y reproductive de lase xplotaciones ganaderas del bajo Cauca y el litoral Atlántico antioqueños. Haciendas la Leyenda y la Candelaria. Revista Colombiana de Ciencias Pecuarias 15:293-301.
Grajales, H.; Hernández, A and Prieto, E. (2006). Edad y peso a la pubertad y su relación con la eficiencia reproductiva de grupos raciales bovinos en el trópico colombiano. Livestock Research for Rural Development 18(10).

Groeneveld, E.; Kovac, M. and Mielenz, N. (2010). VCE User's Guide and Reference Manual Version 6.0.ft p://ft p.tzv.fal.de/pub/vce6/doc/ vce6-manual-3.1A4.pdf.

Haile-Mariam. M.; Bowman, P. J. and Goddard, M. E. (2003). Genetic and environmental relationship among caving interval, survival, persistency of milk yield and somatic cell count in dairy cattle. J. Dairy Sci., 80: 189-200.

Hammoud, M. H. (2013). Genetic aspects of some first lactation traits of Holstein cows in Egypt, Alex. J. Agric. Res., Vol. 58.295-300.

Ibeawuchi, J. A. and Dangut, A. (1996). Influence of stage of lactation on milk constituents of Bunaji (Zebu) cattle in a hot humid tropical environment. Discovery and Innovation 8: 249-56.

Khattab, A. S., Hulya, A. and Lila, B. (2005). Variances of direct and maternal genetic effects for milk yield and age at first calving in a herd of Friesian cattle in Egypt. Arch. Tierz., Dummerstorf. 48: 24-31.

Khattab, A. S.; El-Awady, H. G.; El-Arian, M.N. and Kawther. A. Mourad. (2003). Genetic analysis of some performance traits using an animal model in a herd of Egyptian Buffaloes. Egyptian. J. Anim. Prod., 40: 15-26.

Lee, D. H. and Han, K. J. (2004). Genetic relationship between milk production, calving ease and days open at first parity in Holstein cows, Asian-Aust. J. Anim. Sci., 17: 153-158.

Marai, I. F. M.; Daader, A. H.; Soliman, A. M. and ElMenshawy, S. M. S. (2009). Non-genetic factors affecting growth and reproduction traits of buffaloes under dry management housing (in subtropical environment) in Egypt. Livestock Research for Rural Development. Volume 21, Article \#30.

Mark, T.; Fikse, W. F.; Emanuelson, U. and Philipsson, J. (2002). International genetic evaluations of Holstein sires for milk somatic cell and clinical mastitis. J. Dairy Sci., 85:2384-2392.

Marl, (2016). Ministry of Agriculture and land reclamation

Mourad, M. A. and Khattab, A. S. (2009). A comparison between different selection indices for some productive traits on Egyptian buffaloes. Archiv Tierzuchi. 52: 476 - 484.

Mostafa, M. A.; Khattab, A. S.; Set El-Habaeib. Awad; Tizsér, J. (2012). Genetic parameters for buffalo milk yield and milk quality traits using animal model. Aweth. Animal welfare, ethology and housing systems $8: 175-181$. 
Mostafa, M. A.; Enas .A. Bader.; Khattab, A. S. (2013). Variances of direct and maternal genetic effects for milk yield and its composition in a herd of Friesian cows in Egypt. J. Anim. Prod., 4 : 493499.
Zafar, M. A. and Rehman A. H. S. U. (2008). study of some performance traits in sahiwal cows during different periods, Pakistan Vet. J, 28: 84-88.

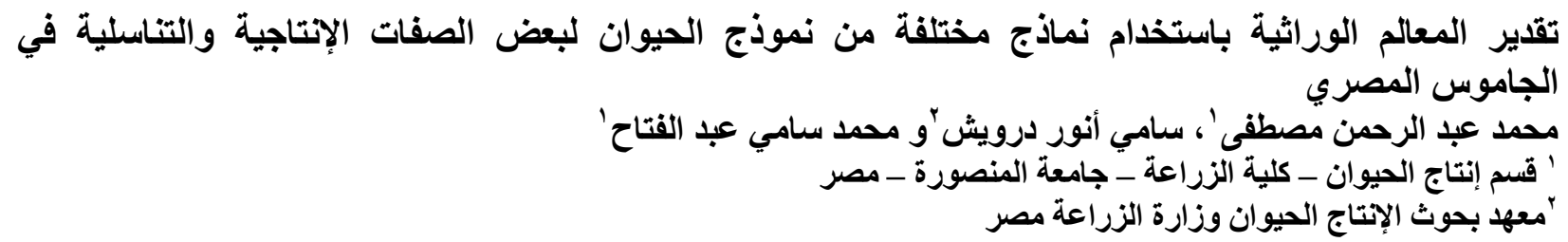

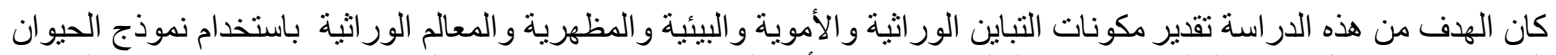

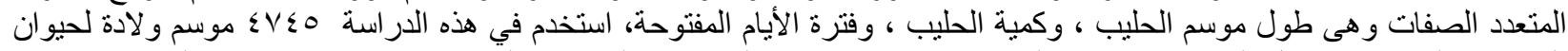

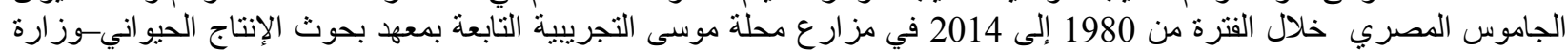

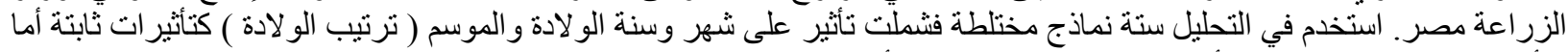

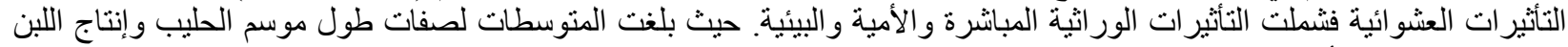

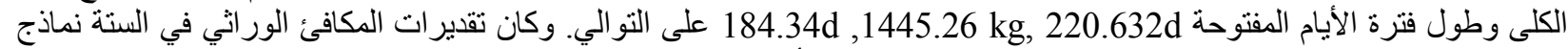

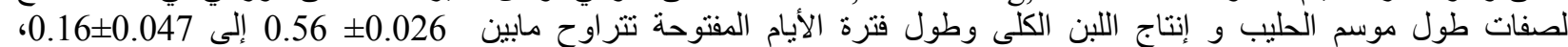

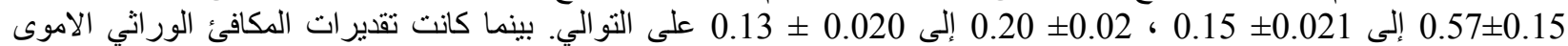

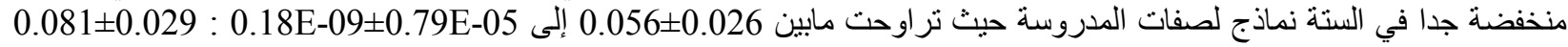

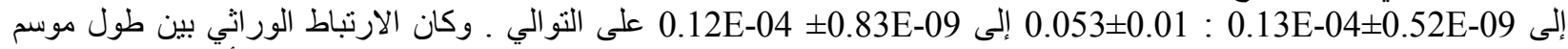

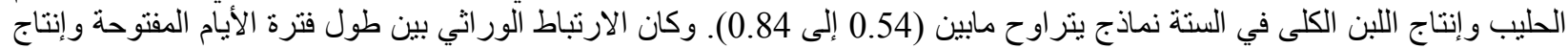

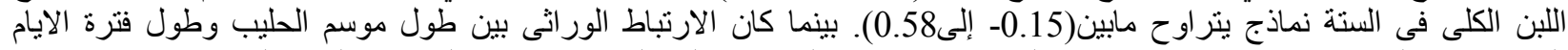

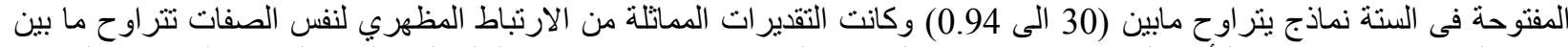

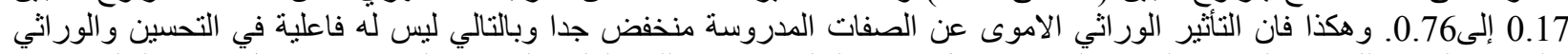

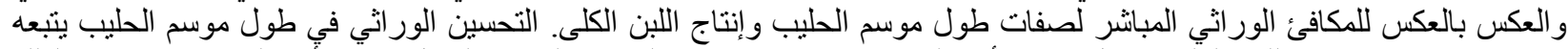

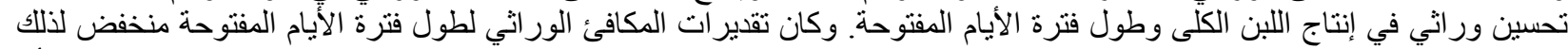

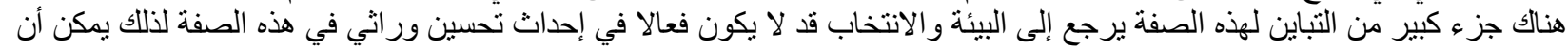

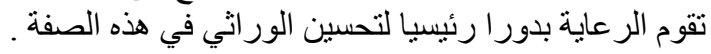

